\title{
ACTORES SOCIALES RURALES \\ Y LA NACIÓN MEXICANA FRENTE \\ A LOS MEGAPROYECTOS MINEROS
}

\author{
Roberto Diego Quintana*
}

Fecha de recepción: 28 de enero de 2014. Fecha de aceptación: 28 de julio de 2014.

\begin{abstract}
RESUMEN
Este trabajo aborda el tema del proceso de acumulación por desposesión por medio del cual las tierras de los campesinos e indígenas son usufructuadas por corporaciones trasnacionales que llevan a cabo actividades de minería a cielo abierto. Asimismo, se argumenta sobre los factores legislativos, político ideológicos y de abuso de autoridad que han conllevado a la situación actual, donde cerca de $17 \%$ del territorio nacional se encuentra concesionada a dichas corporaciones en el 2013, atentando contra la territorialidad de comunidades campesinas y pueblos originarios, así como de la soberanía de la nación. Aquí se plantean estrategias posibles para defender los recursos y el territorio de estos procesos de despojo.
\end{abstract}

Palabras clave: minería, recursos minerales, trasnacionales, comunidades campesinas, concesión de licencias.

Clasificación JEL: D45, E22, F21, H71, L71, L72, L78.

\section{Rural Social Actors and Mining Mega-Projects in MeXico}

\begin{abstract}
This work deals with accumulation by dispossession, a process by which multinational corporations engaged in open-pit mining have availed themselves of the lands of farmers and indigenous peoples. Specifically, it is concerned with legislative, political and ideological factors, as well as the abuse of authority brought on by the current situation, in which nearly $17 \%$ of the national territory was under concession to these companies as of 2013. This is an attack on the communities and territories of farmers and original peoples, not to mention national sovereignty. With this in mind, this study proposes some potential strategies to defend the resources and territory from this dispossession.
\end{abstract}

Key Words: Mining, mineral resources, multinational corporations, farming communities, concession of permits.

\footnotetext{
* Universidad Autónoma Metropolitana, Unidad Xochimilco, México. rdq@correo.xoc.uam.mx
} 


\section{ACTEURS SOCIAUX RURAUX ET LA NATION MEXICAINE FACE AUX MÉGAPROJETS MINIERS}

\section{Résumé}

Ce travail aborde le thème du processus d'accumulation par dépossession au travers duquel les terres des paysans et des Indiens sont exploitées par des corporations transnationales qui mènent des activités minières à ciel ouvert. Il montre les facteurs législatifs, politico-idéologiques et d'abus d'autorité qui ont conjointement mené à la situation actuelle où près de $17 \%$ du territoire national se retrouve octroyé en concession à ces corporations en 2013, en atteinte à la territorialité de communautés paysannes et peuples originels ainsi qu'à la souveraineté de la nation. Il est ici proposé des stratégies possibles pour défendre les ressources et le territoire de ces processus de dépouillement.

Mots clés: mines, ressources minérales, transnationales, communautés paysannes, concession de licences.

\section{ATORES SOCIAIS RURAIS E A NAÇÃo MEXICANA FRENTE AOS MEGA-PROJETOS MINEIROS}

\section{Resumo}

Este trabalho aborda o tema do processo de acumulação por espoliação por meio do qual a terras dos campesinos e indígenas são usufruídas por corporações transnacionais que leva a cabo atividades de mineração a céu aberto. Também, se argumenta sobre os fatores legislativos, políticos ideológicos e de abuso de autoridade que levaram à atual situação, na qual, em 2013, aproximadamente $17 \%$ do território nacional está concessionado a ditas corporaçóes, atentando em contra a territorialidade de comunidades campesinas e povos originários, assim como a soberania da nação. Aqui projetam possíveis estratégias para defender os recursos e o território desses processos de despojo.

Palavras-chave: mineração, transnacionais, comunidades campesinas, concessão de licenças.

\section{农村社会角色与墨西哥的大型矿业项目}

摘要:

本文的研究是有关剥夺土地所有权的积累过程, 即跨国公司从农民和原著 居民手中获得土地从事矿业开发。具体而言, 这涉及到立法、政治、意识 形态多个因素以及当前形势下的行政权力不当使用。截止到2013年，这 导致了全国 17\% 的土地以特许经营的方式受让给了跨国公司。这是对农民 和原著居民土地的侵犯，更不用说国家主权了。以此为出发点，本文提出 了几个保护资源和土地的战略建议。

关键词: 矿业 矿业资源跨国公司农业社区 特许经营 
Nuestra derrota estuvo siempre implícita en la victoria ajena; nuestra riqueza ha generado siempre nuestra pobreza para alimentar la prosperidad de otros: los imperios y sus caporales nativos.

Eduardo Galeano

Las venas abiertas de América Latina

\section{INTRODUCCIÓN}

En países de menor desarrollo económico, la nación y el Estado, en sus distintas acepciones e interpretaciones, suelen estar en entredicho, ante el desempeńo de este último, frente al embate de los intereses del pequeño y gran capital por usufructuar y explotar los recursos naturales de las comunidades rurales y de los pueblos originarios. La aparente confluencia de intereses que se ha producido entre los actores que privilegian la ganancia y quienes debieran tener por mandato dirigir los destinos de sus pueblos, ha llegado en muchos rincones del mundo a niveles desafortunados, incluso ciñéndose al paradigma neoliberal, y mucho más aún, tratándose de estados cuyos discursos e ideología parecieran ofrecer vías alternas a este modelo, más cercanas a los campesinos y pueblos originarios, muchos de ellos confrontados con los intereses de quienes están ávidos por hacer negocio con recursos que en principio les son ajenos.

Este trabajo aborda el proceso de "acumulación por desposesión"1, por medio del cual, los recursos minerales están pasando a ser usufructuados por la iniciativa privada: específicamente por corporaciones trasnacionales. En un segundo apartado se argumenta sobre los factores legislativos y político ideológicos que han conllevado a que a finales de 2013 cerca de $17 \%$ del territorio nacional se encuentre concesionado a dichas corporaciones (Caballero, 2013), atentando contra la soberanía de comunidades campesinas e indígenas de la nación. En las reflexiones finales se plantean estrategias posibles para defender los recursos y el territorio de estos procesos de despojo.

\section{LA DESPOSESIÓN DEL SUBSUELO Y DEL TERRITORIO}

En tiempos neoliberales, el gobierno ha otorgado concesiones de exploración para buscar minerales a corporaciones trasnacionales mineras. Quienes han estudiado esto informan que hasta el 2013 ya se habían dado 27000 concesiones mineras que abarcan una superficie equiparable de $17 \%$ del territorio 
nacional, o sea, 32.5 millones de hectáreas. Puesto desde otra perspectiva, esto representa la tercera parte de las tierras de ejidos y comunidades (Caballero, 2013). ${ }^{2}$

Para el 2013 ya se cuenta con 2611 sociedades mineras, de las cuales 301 son grandes corporaciones trasnacionales, todas ellas tras la búsqueda y la explotación de minerales metálicos y no metálicos, entre ellos las tierras raras. ${ }^{3,4}$ Muchas en fase de exploración, y pocas ya operan con esta tecnología; en casi todas ellas ha habido inconformidad, rebelión, conflictos, cláusulas de contratos de arrendamiento vagas e incumplidas, y promesas de convenios, así como sentencias judiciales tergiversadas. En lo sustancial, este tipo de minería está dejando tras su paso un sinnúmero de conflictos con las comunidades, así como una polarización y marginación social, pérdida de territorialidad, y deterioro ecológico y paisajístico para la población nativa y, como contraparte, impresionantes ganancias millonarias para las mineras. De acuerdo con González (2013), citando información de Myriam Saade:

México es uno de los cuatro países de América Latina que acumulan más conflictos socioambientales provocados por empresas mineras en cuanto a contaminación, restricción o escasez de agua, falta de consulta previa a las comunidades, disputas territoriales, desplazamiento de pueblos originarios, cambios de uso de suelo, violaciones de derechos humanos e incumplimiento de políticas de responsabilidad social corporativa, pero también por la repartición de rentas e ingresos tributarios provenientes de las actividades mineras, indica un estudio de la Comisión Económica para América Latina y el Caribe (Cepal).

Por citar algunos ejemplos, cabe mencionar el caso del complejo minero "El Peńasquito" en Mazapil, Zacatecas, la mina a tajo abierto más productiva en América Latina y la segunda en escala mundial, propiedad de la minera canadiense Gold Corp, que se encuentra explotando el subsuelo del ejido Cedros, entre otros. ${ }^{5}$ En mayo de 2009, bloquearon la entrada a la mina 435 ejidatarios con sus familias, impidiendo el paso a más de 3000 trabajadores, exigiendo un pago justo por la explotación que están haciendo de sus tierras (Jiménez, 2009). Para estos pobladores rurales su vida ya es otra, han perdido su tierra de cultivo y también su territorio, pues rentaron a la minera 6000 hectáreas, incluidas sus tierras de pastoreo y sus veredas, y hasta el agua que ahora escasea en el pueblo. ${ }^{6}$

La minera va a obtener en 19 ańos 13 millones de onzas de oro, que a un precio estimado de 2000.00 dólares la onza da la impresionante cantidad de 26000 millones de dólares. Como contraparte, los ejidatarios tienen que con- 
formarse con la mísera renta que recibieron por arrendar sus tierras: 50000.00 pesos por cada familia por un periodo de 30 años (Valadez, 2009).

La pérdida de territorialidad ha sido mayor para algunos, como es el caso del poblado que paradójicamente dio su nombre a la mina: "El Peñasquito", y que para su infortunio Golp Corp detectó una de las vetas metalíferas más ricas justo debajo de sus casas y de la comunidad. Esta situación generó presiones y negociaciones que derivaron en el desplazamiento forzado de los peñasquenses, con enseres domésticos, animales y muertos del panteón, hacia un nuevo pueblo rural edificado por la minera, sin tener mucha idea del tipo de vivienda idónea para esta población rural (Panico y Garibay, 2010).

La triste historia de estos ejidos y sus habitantes no ha terminado aún. Cuando la minera deje de explotar el lugar habrá en sus tierras dos enormes "cráteres"; el denominado Peñasco tendrá aproximadamente 600 metros de profundidad y 1500 de diámetro, y el de Chile Colorado medirá 550 metros de profundidad y 800 de diámetro y, de acuerdo con el marco legal, quienes firmaron los contratos de arrendamiento serán corresponsables del deterioro ambiental y paisajístico y, por lo tanto, al migrar la minera, se quedarán con la responsabilidad de arreglar semejante deterioro. ${ }^{7}$

Ya apercibidos de lo que ha ocurrido en otros lugares, los pobladores de otras regiones han reaccionado ante los primeros indicios de actividad minera en su territorialidad. Tal ha sido el caso de la comunidad de Tlamanca en el municipio de Zautla, Puebla y de las 32 comunidades circunvecinas, que ante los trabajos iniciales de una minera china, JDC Minerals, tuvieron a bien movilizarse y tomar por asalto las instalaciones, dando un ultimátum a quienes se encontraban laborando ahí, para que se retiraran del lugar con maquinaria y todo, cosa que se vieron obligados a hacer, quedando la organización regional, creada de exprofeso, el Consejo en Defensa del Territorio Tiyat-Tlalli (tierra en náhuatl y en totonaco) a la espera de que la minera se vuelva a aparecer acompañada de la policía estatal, tal y como ha sucedido en otros lugares.

Este Consejo ha iniciado acciones para impedir que se lleven a cabo inversiones de corporaciones en la región que vayan en contra de los intereses de sus habitantes. A finales de enero del 2013 se movilizaron para apoyar a miembros de la comunidad de Olintla que se opone a la construcción de una presa hidroeléctrica del Grupo México, cuya agua y energía eléctrica al parecer estarían destinadas a una nueva mina a cielo abierto en la región. A la reunión llegaron golpeadores dirigidos por el alcalde del PRI, que está en contubernio con este Grupo, y que intentó boicotear el trabajo del Consejo para alertar a la población de las consecuencias que va a tener construir esta presa. Los asistentes a la reunión estuvieron prácticamente secuestrados por varias horas, bajo 
amenazas de linchamiento y de quemar sus vehículos. Esta situación refleja el clima de tensión y de división que este tipo de intervenciones externas están generando en una región donde se tiene pensado desarrollar 22 proyectos mineros y seis hidroeléctricas — según la Asociación de Cronistas Historiadores y Narradores de la Sierra Norte (García, 2013).

Hay regiones bajo amenaza de desarrollos mineros a cielo abierto donde el trabajo de concientización de la población se ha adelantado al de convencimiento de las corporaciones trasnacionales coludidas con gobiernos e instituciones federales, estatales y municipales. Tal es el caso de la región de Actopan, donde la minera canadiense Gold Group Mining Corp está interesada en explotar oro, plata y cobre en un cerro denominado "La Paila". A esta región han llegado grupos ambientalistas, académicos y organizaciones regionales para advertir a los pobladores el peligro en ciernes para que defiendan su territorio (Huerta, 2010).

Esta debacle socioambiental no es sólo de México, por todos los rincones de América Latina, sin importar ideología ni proyecto de nación, aparecen corporaciones trasnacionales mineras cooptando y corrompiendo autoridades nacionales y locales para lograr entrar a las vetas y depósitos de minerales en el subsuelo. Hoy en día hay cráteres abiertos en México, en Guatemala, en Chile; hasta en países con gobiernos antineoliberales como son Bolivia, Ecuador y Argentina. Todos estos "desarrollos" han venido a generar serios conflictos con la población local. ${ }^{8}$ Lo paradójico de la situación es que al hacer el recuento de ganancias y pérdidas, salvo las corporaciones mineras, que obtienen ganancias de alrededor de $80 \%$ sobre los costos de producción, el resto de los actores no parecieran beneficiarse sustancialmente de estas explotaciones (Garibay y Balzaretti, 2009).

Ciertamente, el rosario de minas paradas por la acción ciudadana organizada, teniendo en contra a sus gobiernos, sigue sumando cuentas: Tambo Grande, Perú; Esquel, Argentina; Intag y Sacayaru, Ecuador; Wirikuta, México, mas son muchas más las que siguen operando a pesar de la oposición ciudadana e incluso de decisiones judiciales que ordenan parar la explotación, como es el caso de la Minera San Javier en México, o Sipakapa en Guatemala, al contar con el beneplácito implícito de quienes detentan los cargos gubernamentales por donde transitan estas decisiones. ${ }^{9}$

En México el caso de las explotaciones mineras, la depredación no podía ser más grande, ya que estas corporaciones están extrayendo recursos no renovables de la nación, es decir, cada gramo de oro o plata que extraen y sacan del país, es un gramo menos que le queda a sus habitantes y a las futuras generaciones. Por si fuera poco, estas corporaciones no están pagando el mineral 
que extraen y se llevan, dado que no se considera ningún concepto relacionado con la cantidad de mineral extraído y procesado. ${ }^{10}$ Quienes han firmado las concesiones de parte del gobierno, en los términos en que lo han hecho, están regalando los recursos naturales al no asignarles un precio, a cambio de generar algunas fuentes de empleo y de un modesto ingreso a las arcas de la Secretaría de Hacienda por medio de una especie de "impuesto", calculado de acuerdo a las hectáreas que cada explotación tiene en usufructo, ${ }^{11}$ sin diferenciar el tipo ni la cantidad de mineral extraído. ${ }^{12}$

Con el fin de dar una idea de la desproporción de las cifras, la diferencia entre las ganancias de estas mineras y su aporte al erario es por demás abismal ya que por cada peso aportado por derechos mineros las corporaciones trasnacionales obtuvieron entre 2005 y 2010 , en promedio, 84.42 pesos, es decir, una diferencia superior a $8000 \%$ (Fernández, 2012). ${ }^{13}$

A lo anterior cabe agregar que los precios de la mayoría de los metales preciosos y no tan preciosos se han mantenido al alza, lo que incrementa todavía más las ganancias de estas empresas.

En lo que respecta al valor de la producción minero-metalúrgica, los datos del gobierno federal resaltan que durante enero-mayo de 2011 el valor de la producción fue superior en $50.1 \%$ respecto al registrado en 2010 , lo cual se explica por los incrementos de precios de los diferentes grupos de metales y minerales: a) metales preciosos; b) industriales no ferrosos; c) metales y minerales siderúrgicos, y d) minerales no metálicos. Así, diferentes productos han experimentado incrementos de importancia, tales son los casos de los metales preciosos como la plata, que incrementó su valor en $131.9 \%$ en el periodo referido y el oro, que tuvo un ascenso de más de $35.9 \%$ de su valor. La situación se repite con otros minerales como el cobre con un incremento de $91.9 \%$, el fierro $27.5 \%$, el carbón $43.5 \%$ y el azufre 63.9\%, entre otros (Presidencia de la República, 2011: 249-254).

En particular, cabe resaltar el caso del oro, cuya cotización en los mercados internacionales ha alcanzado niveles históricos.

Durante 2010, el promedio del precio anual del oro fue de 1224.00 dólares por onza, lo que representó un incremento de $25.9 \%$ con respecto a su precio promedio en 2009 que fue de 972.35 dólares. En 2011, los precios del oro continuaron incrementándose. De acuerdo con los indicadores divulgados por el periódico británico especializado en mercados bursátiles Financial Times, el precio de la onza de oro (31.1034 gramos) alcanzó los 1710.00 dólares al 28 de noviembre de 2011 y se espera que llegue a rebasar los 2000.00 dólares por onza (González, 2011: 12). 
El regalo de los recursos naturales de parte del poder ejecutivo, la bonanza en los precios internacionales de los metales y las innovaciones tecnológicas de la minería a cielo abierto han llevado a la Cámara Minera de México (Camimex) a declarar que "nunca en la historia del país se había producido tanto oro y plata como en el 2010, estos volúmenes de producción permitieron al país recuperar también el primer lugar" (Camimex, 2011:30-31); olvidándose esta cámara que esa producción no es realmente nacional sino principalmente de corporaciones trasnacionales, y que ese primer lugar es de ellas, cuyas ganancias, e incluso el metal mismo en lingotes, en su mayoría, abandonan el país al no haber restricciones en la repatriación de utilidades. ${ }^{14}$

Desde otro punto de vista, más que orgullo, entristece saber que el volumen físico del oro obtenido entre 2000 y 2010 representa más del doble del extraído en 300 años de colonización española en México; de 1521 a 1830 se extrajeron 191825 kilos y de 2000 a 2010 fueron 419 097. Y con relación a la plata, más de la mitad del total extraído durante ese mismo periodo fue de 56144 kilos y 33 465, respectivamente (INEGI, 2010: 3-4; Camimex, 2011: 76-77).

\section{LA ACUMULACIÓN POR DESPOSESIÓN Y LAS DIFERENTES CONCEPCIONES DE NACIÓN Y DEL ESTADO MEXICANO}

Nuestras clases dominantes no tienen el menor interés en averiguar si el patriotismo podría resultar más rentable que la traición o si la mendicidad es la única forma posible de la política internacional.

Eduardo Galeano

Las venas abiertas de América Latina

La dramática situación se debe a la "venta" de los recursos naturales de todos los mexicanos, de nuestra nación, legalmente llevada a cabo por el gobierno federal, por medio de las secretarías de Economía y de Energía, mas de muy cuestionable legitimidad, dada la amañada, e incluso inexistente, consulta previa a los habitantes afectados por estas concesiones, por lo que se está poniendo en entredicho los fundamentos de la nación, en casi todas sus acepciones.

Ciertamente, hay un choque de trenes entre las diferentes propuestas de nación y los cambios que, relacionados a ellas, se requieren llevar a cabo para posicionar mejor a México en la globalización. Mientras que los gobiernos neoliberales han tomado entre los indicadores fundamentales de desarrollo económico el monto de inversión extranjera, hay quienes cuestionan seriamente los beneficios de ésta y hablan más bien de un saqueo de recursos natu- 
rales, energéticos, genéticos y humanos, abogando por una inversión estatal y nacional, y de requerirse, una inversión extranjera ceñida a los intereses de la nación y, por lo tanto, de sus ciudadanos.

En este mismo tenor, los adeptos al neoliberalismo y, por ende, al tótem del libre mercado, han ido logrando hacer cambios radicales en la Constitución mexicana y en el entramado legal que de ella se deriva, con el fin de abrir al libre mercado nacional, pero sobre todo al internacional, a todos los mercados: financiero, bienes y servicios, tierras y aguas, laboral y tecnológico.

Como contraparte, ha habido propuestas a favor de cambios contrarios a esta tendencia neoliberal, que sin negar la globalización, plantean retomar la rectoría del Estado y de la ciudadanía, poniendo controles a estos mercados con el fin de fomentar un desarrollo económico, social, político y cultural de la nación en su diversidad. Estas otras propuestas, de corte nacionalista, ${ }^{15}$ sobra decirlo, no han salido del material impreso que las contiene, y no se han materializado en modificaciones constitucionales, o en leyes, o en acciones gubernamentales de ningún tipo por el simple hecho de que son los adeptos al neoliberalismo quienes detentan el poder político nacional.

\section{EL ORIGEN}

El contrato social establecido en la Constitución mexicana del 1917 es fiel reflejo de la diáspora social y política de la posrevolución, en su redacción se consideró que para arrejuntar las trizas de la sociedad que emergía tras la fratricida lucha se requería limar toda diferencia étnica, cultural, política, jurídica y social. Esta concepción homologadora se vino a amalgamar con la de un Estado autoritario, omnipresente, fuertemente corporativizado, en donde la sociedad civil, los actores sociales, poco o nada tenían que decir o hacer frente a ese "Ogro Filantrópico" ${ }^{16}$ que se autoerigía como el benefactor de todos aquellos que en lo nominal planteaba representar y proteger, pero que en los hechos vendría a manipular, cooptar, someter, reprimir, no reconociéndoles ningún derecho en aquellos menesteres autoadscritos a la nación, por intermediación de los hijos predilectos de la Revolución.

Para efecto de los casos citados con anterioridad, tómese como ejemplo al artículo 27 constitucional, en lo referente al sentido de los derechos territoriales y agrarios. Este artículo establece que "la propiedad de las tierras y aguas comprendidas dentro de los límites del territorio nacional, corresponde originariamente a la nación, la cual ha tenido y tiene el derecho de transmitir el dominio de ellas a los particulares, constituyendo la propiedad privada." (Tribunal Superior Agrario, 1994:7). Como se puede intuir de este principio fun- 
damental de la nación, el control sobre la tierra y los recursos naturales, por parte del Estado, como representante, se mantiene aun después de transmitir el dominio a manos sociales o privadas. Más aun, para enfatizar la situación, este mismo artículo establece que: corresponde a la nación el dominio directo de todos los recursos naturales de la plataforma continental y los zócalos submarinos de las islas; de todos los minerales o sustancias en vetas cuya naturaleza sea distinta de los componentes de los terrenos, tales como los minerales o sustancias que en vetas cuya naturaleza sea distinta de los componentes de los terrenos, tales como los minerales de los que se extraigan metales y metaloides utilizados en la industria; los yacimientos de piedras preciosas, de sal gema y las salinas formadas directamente por las aguas marinas; los productos derivados de la descomposición de las rocas, cuando su explotación necesite trabajos subterráneos; los yacimientos minerales u orgánicos de materias susceptibles de ser utilizadas como fertilizantes, los combustibles minerales sólidos; el petróleo y todos los carburos de hidrógeno sólidos, líquidos o gaseosos; y el espacio situado sobre el territorio nacional, en la extensión y términos que fije el derecho internacional (Tribunal Superior Agrario, 1994:8).

Poca cosa. Ante semejante omnipresencia de una entelequia como la nación, no pareciera haber cabida para los actores sociales y sus concretas "matrias".

Si bien, a la luz de los tiempos neoliberales actuales, esta redacción suena anacrónica, cabe considerar que ella es consecuencia de la experiencia pre revolucionaria de hace cerca de 100 años, durante la cual la casi totalidad de las comunidades indígenas y campesinas del país perdieron sus tierras y recursos naturales a manos de compañías deslindadoras y de haciendas, por medio de despojos legalizados fundamentados en las modificaciones liberales a la Constitución de 1856, como fue la Ley Lerdo, así como de la liberalización económica en la que los recursos minerales y los petrolíferos terminaron en manos del capital extranjero. No es de extrañar, por lo tanto, que los hacedores de la carta magna de 1917 buscaran salvaguardar tierras, aguas, territorio y recursos naturales de los intereses privados y del mercado, dejando en manos del Estado su propiedad, y su control.

Paradójicamente, con las reformas neoliberales iniciadas en 1982, en las que la Constitución de 1917 ha sido tasajeada y parchada con miras a facilitar el libre accionar de las fuerzas del mercado y la libre entrada de capital extranjero a México, los preceptos de la misma, arriba mencionados, han sido dejados intactos. Esta situación dista en mucho de ser producto de alguna omisión u olvido. 


\section{EL ANDAMIAJE DE SERPIENTES Y ESCALERAS}

Mantener la propiedad y el control de los recursos naturales de la nación en manos del Estado pareciera haber facilitado que éstos hayan ido cayendo en posesión de corporaciones trasnacionales. Para ello, los hacedores de la política del país han tenido que ir entreverando una compleja urdimbre de serpientes y escaleras por medio de la cual se dificulta el acceso, usufructo y beneficio de los mismos a algunos, mientras que se facilita de ello a otros. Vistos a la distancia, los cambios han sido radicales, mientras que en 1981 los extranjeros de cualquier tipo no podían tener legal y formalmente propiedades en el país, hoy en día ya no tienen limitación alguna, más allá de su capacidad de compra de bienes y conciencias.

Orquestar los cambios en la legislación mexicana para abrir las puertas a la inversión extranjera en la explotación y/o usufructo de los recursos naturales ha requerido de gran dedicación debido a la multiplicidad de artículos constitucionales, leyes reglamentarias, ordenamientos, y demás recovecos relacionados. Para dar una somera idea, allanar este escarpado paisaje legal ha implicado cambios al artículo 27 constitucional, que regula la propiedad de la tierra y de los recursos naturales, así como a sus leyes reglamentarias: agraria, forestal, de aguas, minera. También se han tenido que hacer modificaciones a la Ley General de Bienes Nacionales, la Ley General de Equilibrio Ecológico y Protección al Ambiente, la Ley General para la Prevención y Gestión Integral de Residuos, la Ley de Aguas Nacionales, la Ley de Inversión Extranjera y el Código Civil, entre otras. Estas modificaciones han tenido que seguirse haciendo escaleras abajo hasta limar cualquier contradicción en los reglamentos, así como en los programas, funciones y atribuciones de los organigramas institucionales (López Bárcenas, y Eslava, 2011).

\section{LA LEY Y LA TRAMPA}

El artículo 27 de la Constitución referido arriba, establece claramente que el sinnúmero de recursos mencionados son dominio o propiedad directa de la nación, y que a diferencia de las tierras, su propiedad no puede ser transmitida a particulares. Esta situación se enfatiza en la Ley de Bienes Nacionales que establece que estos recursos están sujetos "al régimen del dominio público de la federación" (artículo 6, párrafo 1), y estarán exclusivamente bajo la jurisdicción de los poderes federales (artículo 9).

Para el nacionalismo extremo hasta ahí va bien la cosa. El problema se empieza a dejar entrever cuando en ese mismo artículo se va aterrizando el 
precepto rector de las formas mediante las cuales estos recursos podrán ser explotados, abriendo la puerta a las concesiones otorgadas a particulares por el Ejecutivo Federal (es decir: Presidente, Secretario de Economía y Secretario de Energía), y más aún, léase bien: "a las sociedades constituidas conforme a las leyes mexicanas", que no quiere decir mexicanas, sino todas aquellas sociedades canadienses, rusas, chinas, chilenas y mexicanas, entre otras, cuya constitución cumpla con lo establecido en las leyes mexicanas (López Bárcenas, y Eslava, 2011). Esta redacción abre de par en par el usufructo de los recursos naturales de la nación a todas las corporaciones trasnacionales, previa adecuación de sus documentos legales a las leyes mexicanas.

\section{LA UTILIDAD PÚBLICA}

La redacción original y actual del artículo 27 constitucional, además de darle la propiedad de los recursos naturales de la nación al Estado, con relación a las concesiones establece que:

La nación tendrá en todo tiempo el derecho [...] de regular, en beneficio social, el aprovechamiento de los elementos naturales susceptibles de apropiación, con objeto de hacer una distribución equitativa de la riqueza pública, cuidar de su conservación, lograr el desarrollo equilibrado del país y el mejoramiento de las condiciones de vida de la población rural y urbana.

Estas salvaguardas parecieran condicionar toda concesión al bienestar social y la sustentabilidad de los recursos naturales. Desgraciadamente, estos loables principios se han quedado tan sólo en el papel, debido a que, con relación a las concesiones dadas a las corporaciones trasnacionales mineras, queda claro que el beneficio es privado, que no habrá equidad en la distribución de los beneficios, que habrá deterioro de los recursos naturales, que no se desarrollará equilibradamente el país y que no se mejorarán las condiciones de vida de sus habitantes.

A pesar de todo lo anterior, tomando como ejemplo a la minería, La Ley Reglamentaria derivada del artículo 27 constitucional correspondiente establece en su artículo 6 que: "la exploración, explotación y beneficio de los minerales o sustancias a los que se refiere esta Ley son de utilidad pública (las cursivas son nuestras), y serán preferentes sobre cualquier otro uso del terreno", esto último, incluyendo la actividad agropecuaria y forestal llevada a cabo por los habitantes de las comunidades indígenas, ejidos y demás formas organizativas del campo, sustento fundamental en sus formas y mundos de vida. 
Esta redacción no es gratuita, a pesar de entrar en flagrante contradicción con la cita del artículo 27 referido arriba, ya que declarar a la minería como de utilidad pública pone en la total indefensión legal a las comunidades rurales de cualquier cuño que quieran defender sus tierras ante una eventual explotación privada, debido a que al ser consideradas de utilidad pública se abre la puerta para su eventual expropiación, en caso de que estas comunidades no lleguen a un "arreglo", de arrendamiento, con la corporación trasnacional agraciada con la concesión, para usufructuar las tierras que el Estado en un principio les concesionó a ellos como comunidad, ejido o propiedad privada. Aquí cabe señalar que, de acuerdo con la Constitución, la utilidad pública sólo se justifica cuando la actividad se relaciona con un bien o servicio público, o cuando ésta es de utilidad social o nacional, y al parecer las concesiones ya mencionadas otorgadas al capital privado no cumplen con ninguna de estas bondades, contraviniendo lo poco del compromiso social que en la Constitución, y más concretamente en su artículo 27, se ha dejado. Ya que lo que se está fomentando es el lucro en detrimento del bien común y de la propiedad social. ${ }^{17}$

\section{LA ORQUESTACIÓN DE LAS CONCESIONES}

Si bien de acuerdo a la Constitución mexicana los recursos naturales de la nación quedan bajo resguardo del Estado, del gobierno federal, y no pueden otorgarse en propiedad a particulares, esto no implica, al final de cuentas, mucho resguardo en realidad, ya que si bien el Estado puede explotarlos directamente, también puede concesionar su uso y aprovechamiento a particulares, que para sus propósitos de enriquecimiento pueden hacer uso y disfrute de los mismos casi como si fueran de ellos.

Dentro del gobierno federal, de acuerdo a la Ley Orgánica de la Administración Pública Federal, corresponde a la Secretaría de Economía otorgar las concesiones mineras, sin que medie en ello el interés público, expresado cuando menos de parte de las comunidades directamente afectadas por las concesiones, es decir, no hay señalamiento expreso que para otorgar una concesión de este tipo se deba consultar a la población por beneficiar o afectar. Esta "consulta", de hacerse posteriormente, tiende a tener un sentido meramente publicitario, resaltando las bondades y los beneficios que conllevará semejante concesión a los pobladores del lugar, evitando con ello posibles resistencias de estos últimos, así como facilitar la anuencia requerida de las autoridades locales para este tipo de explotación, porque si bien la concesión minera es formalmente otorgada por medio de la firma del Secretario de Economía del gobierno federal, el otro documento necesario, es el cambio 
de uso del suelo, usualmente de agropecuario a minero, o eólico, o turístico o urbano, que de acuerdo con el artículo 115, fracción v de la Constitución mexicana debe ser otorgado por la autoridad local, el presidente municipal; el eslabón más débil, que obviamente estará sujeto a un sinnúmero de presiones, para que autorice que una corporación trasnacional se asiente en el espacio físico del municipio. De ahí los conflictos locales que esta situación ha generado, ya que esta autoridad puede firmar el permiso sin que haya obligatoriedad alguna en el artículo mencionado, de hacer una consulta previa a los ciudadanos del municipio para saber su parecer, más allá de los usos y costumbres establecidos en el lugar, y de la legislación internacional como lo es el Convenio 169 de la Organización Internacional del Trabajo (оIт), signada por el gobierno mexicano y, por lo tanto, parte de la legislación vigente del país, que es realmente un referente nominal a la espera de ser llevada a la práctica.

En el caso de la minería, las concesiones son otorgadas por un lapso de 50 años, renovable por otros 50, o sea, en los hechos, por nada más ni nada menos que 100 años. ${ }^{18}$ Por si esto fuera poco, éstas consideran la exploración, la explotación y beneficio de todo recurso que se encuentre dentro de la superficie sujeta a concesión. Es decir, a diferencia de antaño, la concesión no se da con relación a un metal: oro, plata y demás, sino con una superficie. ${ }^{19}$ Así, la intención de la minera puede ser encontrar oro, hallando en su lugar tierras raras, sin que esto perjudique los términos de la concesión.

El gobierno federal, por su parte, deberá facilitar que la empresa logre obtener en usufructo o propiedad los terrenos superficiales bajo los cuales se encuentra el yacimiento por explotar. Para ello, hará uso de todas sus facultades con el fin de convencer a la población que se asienta en la superficie para que lleguen a un buen arreglo con esta compañía que, por lo general, tratará de arrendar la tierra. De haber renuencia u oposición de la población local, la Secretaría de Economía, que otorgó la concesión, puede tramitar la expropiación, dado que, tal y como ya se mencionó, las modificaciones constitucionales han permitido otorgarle a estas actividades el estatus de "utilidad pública".

\section{LAS INCONGRUENCIAS ENTRE EL NUEVO ANDAMIAJE “LEGAL” NEOLIBERAL Y LA LEGISLACIÓN INTERNACIONAL}

Tal vez sin reflexionar seriamente sobre las implicaciones, el gobierno de México firmó en 1992 el Convenio 169 de la OIT, que es un instrumento jurídico internacional vinculante sobre los derechos de los pueblos indígenas y tribales. 
Debido a ello, lo estipulado en este convenio debería estar por encima de la Constitución mexicana y de las leyes federales de México (López Bárcenas, y Eslava, 2011).

De ser así, uno de los preceptos del mencionado Convenio, que el gobierno de México no ha respetado, es el artículo 15 que en su segunda parte establece que: "Los gobiernos deberán establecer o mantener procedimientos con miras a consultar a los pueblos interesados, a fin de determinar si los intereses de esos pueblos serían perjudicados, y en qué medida, antes de emprender o autorizar cualquier programa de prospección o explotación de los recursos existentes en sus tierras."

Los reclamos en este sentido son la norma, ya que la mayor parte de los relatos de miembros de pueblos originarios con relación a mineras, así como para las eólicas, las presas y demás dejan sentir que no fueron consultados previamente, ni se les dio acceso a la información necesaria para decidir con conocimiento sobre el arrendamiento, venta o implicaciones de la expropiación de sus tierras. ${ }^{20}$

En los casos en los que se les ha llegado a informar, esto se ha realizado sobre hechos consumados, ya que los interesados en sus tierras ya tenían la concesión del gobierno federal por conducto de la Secretaría de Economía y su intención era convencerlos para que sus autoridades signaran el cambio de uso del suelo. En muchos casos, cuando las autoridades han firmado este cambio como decisión unipersonal, los lugareños se han ido enterando de los grandes cambios que se les venían encima por medio de rumores, o al ver aparecer por sus tierras brigadas de exploración y maquinaria.

Otra contradicción fundamental que se ha dado en los hechos se relaciona al respeto de las formas y mundos de vida y a la territorialidad de los pueblos originarios. El Convenio 169 establece en su artículo 13 que: "los gobiernos de los estados deben respetar la importancia especial que para las culturas y los valores espirituales de los pueblos interesados reviste su relación con las tierras y territorios $[\ldots]$ ". Cabe aclarar que por territorio se entiende aquí al espacio físico resignificado y resimbolizado por las asociaciones humanas, mismo que considera no sólo la tierra, sino además el agua, la biodiversidad, los recursos naturales, el espacio aéreo, los espacios relevantes para su cultura y para sus mitos y ritos sagrados.

Con relación a lo anterior, y cuando menos nominalmente, las distintas legislaciones derivadas del artículo 27 constitucional se refieren al derecho que tienen los pueblos originarios de lograr la concesión para la explotación de los recursos naturales que se encuentren en sus tierras. A manera de ejemplo, el artículo 13 de la Ley Minera plantea que: "Cuando un terreno se encuentre 
en un área habitada y ocupada por un pueblo o comunidad indígena, y dicho pueblo o comunidad solicite dicho terreno simultáneamente con otra persona o personas, será preferida la solicitud del pueblo o comunidad indígena a efecto de que se otorgue la concesión minera sobre dicho terreno, siempre y cuando cumpla con las condiciones y requisitos que establecen la presente ley y su reglamento".

Sin embargo, para que esta preferencia se materialice, además de que el pueblo originario debe cumplir con todo un listado de "obstáculos", los requisitos y condiciones que se mencionaran posteriormente en la mencionada ley, y más concretamente en el artículo 13 bis, erigen una muralla más infranqueable, ya que para que este derecho pueda materializarse, el pueblo o comunidad indígena deberá cuando menos igualar la mejor propuesta económica que presente otro concursante (López Bárcenas, y Eslava, 2011: 30). Sería realmente inaudito, inédito en la historia, el que una comunidad de un pueblo originario pudiera igualar la oferta de una corporación trasnacional con relación a una concesión minera.

Así las cosas, mientras que un tribunal internacional no meta en cintura al poder ejecutivo de México, y lo obligue a adecuar sus leyes y hechos burocrático administrativos al Convenio 169, todas las buenas intenciones plasmadas en éste, para los pueblos originarios en México, tan sólo representan un referente de lo que debería ser, y no es, dejando un atisbo de esperanza para que en un futuro cercano sí lo sea.

\section{REFLEXIONES FINALES}

En México, los derechos territoriales y los agrarios privados y sociales están constreñidos por los derechos que el Estado se ha auto concedido sobre la propiedad y usufructo de los bienes de la nación. De hecho, es el gobierno, la clase política, con claras expresiones patrimonialistas, la que explota hasta hoy en día los recursos petroleros, ${ }^{21}$ y más aún, es el Poder Ejecutivo el que otorga concesiones sobre los recursos naturales de la nación a empresarios privados sean estos nacionales o extranjeros. Aquellos que por suerte o por fatalidad lleguen a habitar sobre estos recursos, a lo más que pueden aspirar es obtener un pago compensatorio por su tierra que, en general, suele estar muy por debajo del valor comercial, al tiempo que ésta puede ser expropiada, en nombre del interés público, o concesionada por medio de arrendamiento, recibiendo una renta simbólica si se compara con las ganancias obtenidas por los arrendadores. Los beneficios producto de la explotación de esos recursos en parte irán muy 
probablemente a los bolsillos de algunos de los funcionarios públicos involucrados en las concesiones, a las arcas del erario público y, en mucho mayor medida, a las corporaciones privadas agraciadas con la concesión gubernamental. Los anteriores dueños-posesionarios de la tierra habrán sido enajenados de los beneficios obtenidos por la explotación de los recursos que se encuentran por debajo y por encima de su tierra, o cuando mucho, la ironía del caso, éstos serán incluidos posteriormente en la explotación de los recursos como mano de obra asalariada en el mismo espacio, territorio, donde se encuentra su tierra enajenada.

Este ha sido y es la Caja de Pandora de los casos de estudio citados en este trabajo a los cuales se les podría agregar un inmenso rosario de experiencias similares de "acumulación por desposesión", fundamentalmente posibles gracias a la concentración de poder, control y dominio de la nación-Estado sobre la territorialidad nacional, sin que los derechos de la población en sus diferentes localidades, hayan sido reconocidos; en lo que a su territorialidad, autonomía, gobernanza y derechos ciudadanos compete.

Esta situación por sí sola viene a poner en entredicho el mismo contrato social establecido en la Constitución nacional, y pareciera reclamar una refundación de la nación misma, bajo distintos principios fundamentales, en donde se reconozcan y potencien los derechos de la ciudadanía, para que a partir de ellos, ese variopinto, "nosotros", pueda también tener sus derechos, evitando con ello que unos pocos usufructúen lo que es de todos, en la diferencia.

De mantenerse el entramado legal actual, poco puede hacerse para evitar que el Poder Ejecutivo siga otorgando concesiones a las corporaciones privadas. Ciertamente, se requiere que el Congreso de la Nación y la Suprema Corte de Justicia se impregnen de un poco de ética y nacionalismo e impulsen las enmiendas constitucionales y jurídicas pertinentes para controlar este proceso de desposesión de parte del gran capital sobre los recursos de la nación que, en principio, son de todos los mexicanos.

En lo local y lo regional también pueden hacerse, de entrada, trabajos de base con los habitantes de los municipios para que en las elecciones locales, en las de las presidencias municipales, para los comisariados ejidales y de bienes comunales, ganen candidatos comprometidos con sus conciudadanos y no vayan a ceder ante las presiones políticas de los gobiernos federal y estatal para autorizar los cambios en el uso del suelo requeridos para el aterrizaje de las corporaciones privadas sobre su territorio.

Importante es también que este tipo de decisiones sean consultadas a todos los habitantes del municipio, previa información no amañada, tal y como lo establece el Convenio 169 de la oit, y que la decisión sea consensada entre 
todos aquellos que puedan salir beneficiados o afectados por la decisión tomada; esto incluye a los habitantes de comunidades circunvecinas y en el caso de cuencas de ríos a todas aquellas que se encuentren dentro de ella.

En esta línea argumental es conveniente adoptar una estrategia regional que trascienda lo local. Un enfoque que ha ayudado a algunas regiones a mantener un cierto control sobre su territorialidad y a frenar intervenciones de corporaciones privadas ha sido el plan de ordenamiento territorial. Si éste es bien orquestado y se hace de forma participativa, considerando a todos los actores y sus asociaciones en un territorio, se pueden producir propuestas sobre qué actividades desarrollar, tanto de conservación como de producción sustentable. Y si este plan es aprobado por el cabildo del municipio, todas las autoridades por venir deberían de respetarlo. Y más aún, si éste es aprobado por las instancias legislativas y ejecutivas estatales y se llega a publicar en el Diario Oficial del estado, en principio, cualquier concesión federal unilateral sobre este territorio estaría en la ilegalidad.

Ciertamente, lograr recorrer todo este camino requiere de encontrar los apoyos y las fisuras adecuadas en el aparato burocrático, legislativo y administrativo estatal. El camino es ciertamente encrespado, más no hay peor lucha que la que no se hace, y mientras se logra que se otorgue autonomía y territorialidad a los pueblos originarios, y también a los no originarios, sean rurales o urbanos, este camino, ya ha sido recorrido con anterioridad por los actores sociales y sus organizaciones de la región de Cuetzalan en la Sierra Norte de Puebla, y muy bien puede ser recorrido por otros en su diferencia.

\section{NOTAS}

1 Este concepto fue acuñado por David Harvey (2004) para referirse a los procesos mediante los cuales empresas corporativas capitalistas, mayormente trasnacionales, en su búsqueda por maximizar la ganancia — tras la caída en la tasa de ganancia en países desarrollados económicamente-, han enfocado sus inversiones hacia la explotación de recursos naturales en países de menor desarrollo económico, derivando en un proceso de despojo de estos recursos, a pueblos originarios y comunidades campesinas, considerados por estos últimos bienes naturales.

2 Estas cifras son de la Secretaría de Economía. Otras fuentes mencionan una superficie concesionada mucho mayor, como Peniley Ramírez (2013), que menciona 95.8 millones de hectáreas, prácticamente la mitad del país. Méndez y Garduño (2013) dan casi la misma cifra: 96 millones de hectáreas.

3 De estos proyectos, cerca de 500 están asociados con metales preciosos, 14 son polimetálicos; 70 son proyectos asociados con el cobre; 24 con minerales de hierro, y 16 proyectos con otros metales y materiales, como germanio, cobalto, titanio, molibdeno, bismuto, estaño, platino, paladio, antimonio, níquel, wolframio, zeolita-chabazita, barita, pórfidos, boratos, wollastonita y roca fosfórica. 
4 Datos del 2010 dan idea de la nacionalidad de las asociaciones mineras extranjeras: $75 \%$ en Canadá; 15\% en Estados Unidos; 3\% en Australia; 2\% en Reino Unido y Japón; y con cerca de $1 \%$ se encuentran la República Popular China, Corea del Sur, Suiza, Luxemburgo, Chile, India, Italia, Holanda y Perú (Dirección General de Promoción Minera, 2010:16-17).

5 Los ejidos que arrendaron la tierra son Mazapil, Cerro Gordo, Cedros y El Vergel. El ejido de Cedros es el que cedió más tierra.

6 Los pobladores del lugar utilizaban un camino denominado El Bordo para ir a varios ranchos cercanos como Las Mesas y Palmas, y también del pueblo a los terrenos de pastoreo. La tierra que el ejido de Cedros arrendó a la minera incluye parte de este camino, y si bien se negoció que éste se mantuviera para el libre tránsito, la minera tuvo a bien construir una gran presa para almacenar el agua requerida para la extracción de los metales. El conflicto se dio cuando empleados de la minera cerraron el camino. Mas la presa es vital para la minera y, por supuesto, los lugareños tendrán que encontrar otra vía para transitar por lo que alguna vez fue su territorio (Panico y Garibay, 2010).

7 En su artículo 70, la Ley General para la Prevención y Gestión Integral de los Residuos establece que: "los propietarios o poseedores de predios de dominio privado y los titulares de áreas concesionadas, cuyos suelos se encuentren contaminados, serán responsables solidarios de llevar a cabo las acciones de remediación que resulten necesarias [...]".

8 Véase la página Web de "No a la mina": www.noalamina.org/

9 Ibid.

10 De acuerdo con Christian Aid (2009), en un excelente estudio sobre tributación de las corporaciones mineras en América Latina, es evidente que estos países no están siquiera siendo adecuadamente retribuidos por la extracción de sus recursos naturales no renovables. Con relación al pago de impuestos y regalías esta organización menciona que Perú, Guatemala y Honduras, se encuentran dentro del nivel más bajo en el mundo, mencionando muy en particular el caso de México, donde éstas ni siquiera se cobran.

11 En el primer año de operación esos consorcios pagan 5.70 pesos por el uso de una hectárea; en el tercer y cuarto años de vigencia de la concesión, 8.52 pesos. El décimo año se aplica la cuota más elevada por usos de hectárea de 124.74 (Méndez y Garduño, 2013).

12 El artículo 263 de la Ley Federal de Derechos señala que los titulares de concesiones y asignaciones mineras pagarán semestralmente por cada hectárea o fracción concesionada un "derecho sobre minería", cuyo monto oscila entre 5 y 111 pesos.

13 Este aparente descuido del ejecutivo federal llevó a la Junta de Coordinación Política del Senado de la República a un acuerdo mediante el cual el Senado invita a la Cámara de Diputados para que mediante sus comisiones de Hacienda y Crédito Público y de Energía "analicen de manera integral el régimen de derechos mineros vigente en el país". El acuerdo aprobado por la Cámara de Senadores es fundamentado: "atendiendo la gran importancia que reviste esta industria y considerando que los bienes que explotan son propiedad de la nación, y que la tributación que realizan no tiene relación ni con el valor de la producción, ni con los altos precios que registran, ni con las utilidades que se perciben" (Senado de la República, sesión ordinaria celebrada el 27 de octubre de 2011, versión estenográfica, tomada de González, 2011:13). A finales de 2013 en el Congreso de la Unión se debatía sobre el cobro de impuesto a las mineras de $7.5 \%$ sobre sus ingresos, sin que se haya llegado a acuerdos sobre el particular, muy probablemente debido al cabildeo y a las amenazas de retirar inversiones de parte de las corporaciones trasnacionales (Garduño y Méndez, 2013). 


\section{Roberto Diego Quintana}

14 Gold Corp tiene pista aérea en "El Peñasquito". Los lingotes de oro producidos con el mineral extraído del subsuelo mexicano son simplemente cargados en sus aviones y sacados del país.

15 Cito a dos de los más recientes: Denise Dresser (2011) y Lorenzo Meyer (2013).

16 Término utilizado por Octavio Paz para nombrar al Estado mexicano, revista Vuelta, junio de 1987.

17 En relación con la minería y la utilidad pública, véase López Bárcenas y Eslava (2011: 8-9).

18 Artículo 15, párrafo cuarto de la Ley Minera.

19 Artículo 15 de la Ley Minera.

20 Será por ironía o franco desacato de la legislación internacional, que la Semarnat haya tenido a bien otorgar la atribución de llevar a cabo la consulta sobre la implantación de una mina en Tetela de Ocampo, Puebla, precisamente a la compañía minera Prisco de Carlos Slim (Puga, 2013).

21 En diciembre del 2013 el gobierno de Enrique Peña Nieto logró que el Congreso de la Unión aprobara modificaciones trascendentales a la Constitución, abriendo los recursos petroleros a la iniciativa privada.

\section{BIBLIOGRAFÍA}

Caballero, José Luis (2013), "En busca del filo de oro", El Economista, 7 de agosto.

Camimex (Cámara Minera de México) (2011), Informe anual de la Cámara Minera de México 2011, México. (2011), "La industria minera de México", México.

Aid Christian (2009), Socavando a los pobres: reformas tributarias mineras en América Latina, Londres.

Dirección General de Promoción Minera (2010), Estadisticas sobre explotación minera, México, Secretaría de Economía.

Dresser, Denise (2011), El país de uno, México, Editorial Aguilar.

Financial Times, Markets data, Indices gold (consultado el 28 de noviembre de 2011), tomada de González (2011:12), disponible en <www.ft.com/ home/us>.

García, Fermín Alejandro (2013), "Olintla: lo que nos espera”, La Jornada, 1 de febrero.

Garduño, Roberto, y Enrique Méndez (2013), “Amagan mineras canadienses con abandonar el país si aprueban impuesto especial”, La Jornada, 1 de octubre.

(2013), "México, convertido en paraíso fiscal para mineras canadienses”, La Jornada, 6 de octubre. 
Garibay, Claudio, y Alejandra Balzaretti (2009), “Goldcorp y la reciprocidad negativa en el paisaje minero de Mezcala, Guerrero", Desacatos, núm. 30, México, CiEsas, mayo-agosto, pp. 91-110.

González, José de Jesús (2011), "Minería en México. Referencias generales, régimen fiscal, concesiones y propuestas legislativas", Documento de Trabajo, núm. 121, México, Centro de Estudios Sociales y de Opinión Pública, Congreso de la Unión.

González, Susana (2013), "México, uno de los países de AL con más problemas con mineras: Cepal", La Jornada, 20 de octubre.

Harvey, David (2004), "El nuevo imperialismo, acumulación por desposesión", The Socialist Register, Buenos Aires, clacso.

Huerta, Verónica (2010), "Ecologistas llaman a la población de Actopan a no dejarse engañar", Radio Verinfo, 23 de agosto (consultado el 6 de noviembre de 2013), disponible en < http://www.radiover.info/nota.php?id=15659> INEGI (2010), “Estadísticas históricas de México 2009”, México, INEGI.

Jiménez, Paulina (2009), "Cierran mina de oro "El Peńasquito" por abusos de la empresa canadiense Gold Corp", Zócalo Saltillo, 26 de mayo (consultado el 3 de enero de 2013), disponible en <http://www.zocalo.com. $\mathrm{mx} /$ seccion/articulo/Cierran-mina-de-oro-El-Penasquito-por-abusos-dela-empresa-canadiense-Gol>

López Bárcenas, Francisco, y Mayra Montserrat Eslava (2011), El mineral o la vida. La legislación minera en México, México, Centro de Orientación y Asesoría a Pueblos Indígenas/Paz en el árbol/Red IInPIM, A.C.

Méndez, Enrique, y Roberto Garduño (2013), "México, paraíso fiscal para compañías mineras canadienses, revela análisis", La Jornada, 17 de octubre.

Meyer, Lorenzo (2013), Nuestra tarjeta persistente: la democracia autoritaria en México, México, Debate.

Panico, Francesco, y Claudio Garibay (2010), "Minería y territorio: una mirada al conflicto desde Mazapil, Zacatecas (México)," Fronteras de la Historia, vol. 15-1, enero-junio, Colombia, Instituto Colombiano de Antropología e Historia, pp. 61-84.

Presidencia de la República (2011), Quinto Informe de Gobierno, Productividad y competitividad, Sector Minero, México; tomada de González (2011:3).

Puga, Javier (2013), "Semarnat defiende a la minera, acusa Tetela de Ocampo", La Jornada de Oriente, 31 de octubre.

Ramírez, Peniley (2013), "Gas shale: la nueva mina de oro", Reporte indigo, 16 de diciembre (consultado el 24 de diciembre de 2013), disponible en 
Roberto Diego Quintana

<http://www.reporteindigo.com/reporte/mexico/gas-shale-la-nueva-mina-de-oro>

Saade, Miryam (2013), Desarrollo minero y conflictos socioambientales. Los casos de México, Colombia y Perú, serie de Macroeconomía del Desarrollo, Santiago de Chile, CEPAL.

Congreso de los Estados Unidos Mexicanos (1994), Legislación Agraria, México, Tribunal Superior Agrario.

Valadez, Alfredo (2009), "Mazapil: dorada miseria”, La Jornada, 5 de enero. 